\title{
Role of hepatic de novo lipogenesis in the development of fasting-induced fatty liver in the American mink (Neovison vison)
}

\author{
Kirsti Rouvinen-Watt ${ }^{1 *}$, Lora Harris ${ }^{1}$, Morag Dick $^{1}$, Catherine Pal ${ }^{1}$, Sha Lei ${ }^{1,2}$, Anne-Mari Mustonen ${ }^{3,4}$ \\ and Petteri Nieminen ${ }^{3,4}$ \\ ${ }^{1}$ Department of Plant and Animal Sciences, Nova Scotia Agricultural College, PO Box 550, Truro, NS, Canada B2N 5E3 \\ ${ }^{2}$ Department of Bioscience and Biotechnology, Dalian University of Technology, Dalian 116024, People's Republic of China \\ ${ }^{3}$ Institute of Biomedicine/Anatomy, Faculty of Health Sciences, School of Medicine, University of Eastern Finland, \\ PO Box 1627, Kuopio FI-70211, Finland \\ ${ }^{4}$ Department of Biology, Faculty of Science and Forestry, University of Eastern Finland, PO Box 111, Joensuu FI-80101, \\ Finland
}

(Submitted 9 August 2011 - Final revision received 20 October 2011 - Accepted 10 November 2011 - First published online 3 January 2012)

\begin{abstract}
American mink (Neovison vison) develop fatty liver quickly in response to food deprivation, which results in preferential mobilisation of $n$-3 PUFA. The altered n-3:n-6 PUFA ratio in the liver may activate the endocannabinoid system resulting in increased lipid synthesis. The objective of the present study was to investigate the effects of feeding intensity ( 80 or $120 \%$ RDA), dietary fat source ( $n$ - $3, n-6$ or $n-9$ fatty acids (FA)) and short-term fasting (1-7d) on hepatic de novo lipogenesis (DNL) and the development of fatty liver in mink. Significantly elevated expression of mRNA encoding for acetyl-CoA carboxylase-1 (ACC-1) and FA synthase (FAS) was observed in the liver of mink fasted for $5-7 \mathrm{~d}$, while upon re-feeding for $28 \mathrm{~d}$ after a $7 \mathrm{~d}$ food deprivation, DNL returned to pre-fasting levels. The females had a higher expression of ACC-1 and FAS mRNA than the males. In the non-fasted animals, dietary fat source and feeding intensity had significant effects on ACC-1 mRNA. The highest levels were observed in the mink fed the rapeseed oil ( $n$-9) diet at $80 \%$ RDA, while the lowest levels were seen when the same diet was fed at $120 \%$ RDA. For FAS, the highest gene expression was seen in the fasted mink fed at $80 \%$ RDA and the lowest in the non-fasted mink fed at $80 \%$. It is concluded that short-term food deprivation induces hepatic lipidosis in mink and that during this process, hepatic DNL further exacerbates liver fat accumulation.
\end{abstract}

Key words: Acetyl-CoA carboxylase: De novo lipogenesis: Fatty acid synthase: Hepatic lipidosis: Hepatic steatosis

The pathophysiology of nursing sickness and the associated fatty liver syndrome in the American mink (Neovison vison) show similarity to type 2 diabetes $^{(1)}$ and the non-alcoholic fatty liver disease (NAFLD) of humans ${ }^{(2,3)}$. Fatty liver (hepatic lipidosis/steatosis) in mink may be caused by several factors, including amino acid or fatty acid (FA) imbalance, excess dietary carbohydrate, deficiencies of choline and vitamin $\mathrm{B}$, poor feed quality, obesity and restricted feeding ${ }^{(4-6)}$. During food deprivation, the intra-abdominal body fat depots are hydrolysed more readily relative to the weight of the depot before fasting when compared with subcutaneous $\mathrm{fat}^{(3,6,7)}$, and rapid body weight (BW) loss is associated with the preferential mobilisation of $n-3$ PUFA resulting in an unfavourable $n-3: n-6$ PUFA balance in the mink and also in other mustelid species $^{(3,7-9)}$. The mink is also highly responsive to dietary manipulation, and the FA composition of its tissues readily reflects that of the dietary FA supply ${ }^{(10,11)}$.

In humans, NAFLD is a common finding in type 2 diabetes and is considered to be a manifestation of insulin resistance ${ }^{(2)}$. It is characterised by an unfavourable $n-3: n-6$ PUFA ratio ${ }^{(12)}$. The over-representation of $n-6$ PUFA in the body results in increased percentages of these FA in tissue phospholipids, including the cell membranes of blood cells and hepatocytes $^{(13,14)}$. This in turn augments the synthesis of arachidonic acid (20:4n-6)-derived eicosanoids and shifts the physiological state of the body to pro-inflammatory and pro-thrombotic. Long-chain PUFA (LC-PUFA) also inhibit the transcription of lipogenic and glycolytic genes ${ }^{(12,15)}$, but induce the expression of genes encoding FA oxidation through the PPAR- $\alpha^{(16)}$. As $n$-3 LC-PUFA activate PPAR- $\alpha$ more effectively than $n-6$

Abbreviations: ACC-1, acetyl-COA carboxylase-1; BW, body weight; DNL, de novo lipogenesis; FA, fatty acid; FAS, fatty acid synthase; GAPDH, glyceraldehyde-3-phosphate dehydrogenase; HPRT1, hypoxanthine phosphoribosyltransferase 1; LC-PUFA, long-chain PUFA; NAFLD, non-alcoholic fatty liver disease; RT-qPCR, quantitative real-time PCR; SREBP, sterol regulatory element-binding protein. 
LC-PUFA $^{(17)}$, a decrease in hepatic lipid oxidation may ensue. As a result, $n-3$ PUFA depletion may favour FA and TAG synthesis over hydrolysis and FA oxidation and impair lipid export from the liver by suppressing VLDL secretion ${ }^{(12)}$. The altered n-3:n-6 PUFA ratio may also be important with regard to the activation of the endocannabinoid system, which is up-regulated in obesity ${ }^{(18)}$. Activation of the cannabinoid receptor 1 in the liver can also play a key role in increased lipid production, fatty liver and possibly diet-induced obesity $^{(19)}$. These effects are mediated by the up-regulation of the lipogenic transcription factor sterol regulatory elementbinding protein (SREBP)-1c and its associated enzymes acetyl-CoA carboxylase-1 (ACC-1) and FA synthase (FAS). In obese patients with NAFLD, up-regulation of liver SREBP-1C is found concomitantly with down-regulation of hepatic PPAR- $\alpha$, with the resulting imbalance between lipogenesis and fat oxidation determining the development of steatosis ${ }^{(20)}$. It is also possible that ghrelin acts at least partly by increasing endocannabinoid production in the hypothalamus causing increased food intake following fasting ${ }^{(18)}$. This suggests that endocannabinoid activation is a cause rather than a consequence of obesity. Endocannabinoids are derivatives of, for example, 20:4n-6 and their levels have been shown to be responsive to dietary manipulation ${ }^{(21)}$ and to glucocorticoids ${ }^{(22)}$.

Based on these data, it is plausible that the over-representation of $n-6$ PUFA in the liver, either as a result of preferential $n$-3 PUFA mobilisation during food deprivation or due to dietary imbalance, could trigger the activation of the peripheral and central endocannabinoid pathways. This activation may be responsible for many of the key features observed in the metabolic syndrome including obesity, insulin resistance and hepatic lipidosis. The goal of the present study was to investigate the effects of dietary allowance, food deprivation and FA nutrition on the aetiology of the fatty liver syndrome in mink, and elucidate the role of hepatic de novo lipogenesis (DNL) in liver fat accumulation.

\section{Experimental methods}

\section{Animal experiments}

In Expt I, sixty standard black mink (thirty males and thirty females), 9 months of age, were used to investigate the timeline and characterise the development of hepatic lipidosis in response to food deprivation and liver recovery after re-feeding. For each group, five male and five female mink were fasted for $0,1,3,5$ and $7 \mathrm{~d}$, while one group was fasted for $7 \mathrm{~d}$ followed by normal feeding for $28 \mathrm{~d}$ during January to February (re-fed group; RF). The diet fed before and after fasting contained $32.3 \%$ DM, 3.3\% ash, $13.5 \%$ protein, $6.7 \%$ lipid and $8.7 \%$ carbohydrate of fresh weight, and 5.65 MJ metabolisable energy/kg (Nova Feeds). In Expt II, seventy-two (thirty-six males and thirty-six females), 5-month-old mink of the standard black colour type were used. The mink were divided into three groups with three different diets containing $4.7 \%$ herring oil ( $n$-3 LC-PUFA), soyabean oil ( $n-6$ PUFA) or rapeseed oil ( $n-9$ MUFA, intermediate n-3:n-6 PUFA ratio; Table 1 ). The basal diet consisted of cod filleting offal, pork liver and spleen, extruded barley, maize gluten meal, vitamin-mineral premix, and water. Each diet was fed at 80 or $120 \%$ of the RDA based on the metabolic $\mathrm{BW}$ of $\operatorname{mink}^{(23)}$. The mink were fed with the experimental diets for 10 weeks from September to December. Of the mink representing each diet and feeding intensity, one-half were fasted for $5 \mathrm{~d}$ and the rest were fasted overnight (14h) before being anaesthetised. In both experiments, the animals were anaesthetised with a combination of xylazine $(3.4 \mathrm{mg} /$ $\mathrm{kg} \mathrm{BW})$ and ketamine hydrochloride $(8.5 \mathrm{mg} / \mathrm{kg} \mathrm{BW})$ given as intramuscular injections, and euthanised with an intracardiac injection of pentobarbital sodium $(106 \mathrm{mg} / \mathrm{kg} \mathrm{BW})$. Following euthanasia, samples were obtained from various internal organs and tissues, snap-frozen in liquid $\mathrm{N}_{2}$ and stored at $-80^{\circ} \mathrm{C}$ for subsequent analyses. The FA profiles of all experimental diets have been reported previously ${ }^{(3,7)}$.

Table 1. Nutrient composition and fatty acid profiles of the diets used in Expt II (Least square mean values with their standard errors)

\begin{tabular}{|c|c|c|c|c|c|c|}
\hline & \multicolumn{6}{|c|}{ Experimental diet } \\
\hline & \multicolumn{2}{|c|}{ Herring oil } & \multicolumn{2}{|c|}{ Soyabean oil } & \multicolumn{2}{|c|}{ Rapeseed oil } \\
\hline & Ls mean & SEM & Ls mean & SEM & Ls mean & SEM \\
\hline \multicolumn{7}{|l|}{ Composition (as fed) } \\
\hline$\% \mathrm{DM}$ & 39.08 & 0.74 & 39.77 & 0.91 & 39.49 & 0.46 \\
\hline$\% \mathrm{CP}$ & $15 \cdot 10$ & 0.30 & $15 \cdot 63$ & 0.51 & $14 \cdot 83$ & 0.31 \\
\hline$\% \mathrm{CF}$ & $6 \cdot 72$ & 0.43 & 7.66 & 0.91 & $6 \cdot 52$ & 0.49 \\
\hline$\% \mathrm{CHO}$ & $12 \cdot 50$ & 0.84 & 13.48 & $0 \cdot 19$ & 13.86 & 0.48 \\
\hline$\%$ Ash & 4.04 & 0.19 & 3.84 & $0 \cdot 19$ & 3.75 & 0.32 \\
\hline Metabolisable energy (MJ/kg) & $6 \cdot 36$ & 0.10 & $6 \cdot 90$ & 0.30 & $6 \cdot 41$ & 0.12 \\
\hline \multicolumn{7}{|l|}{ Fatty acid profile ( $\mathrm{mol} \%)$} \\
\hline Total SFA & $25 \cdot 71^{\mathrm{a}}$ & 0.46 & $20 \cdot 38^{\mathrm{b}}$ & 0.41 & $14 \cdot 90^{c}$ & 0.46 \\
\hline Total MUFA & $53 \cdot 17^{\mathrm{a}}$ & 0.29 & $20 \cdot 99^{\mathrm{b}}$ & 0.29 & $53 \cdot 85^{\mathrm{a}}$ & 0.29 \\
\hline Total $n-6$ PUFA & $10 \cdot 83^{c}$ & 0.55 & $47.56^{\mathrm{a}}$ & 0.55 & $22 \cdot 61^{\mathrm{b}}$ & 0.55 \\
\hline $20: 5 n-3$ & $4.05^{\mathrm{a}}$ & 0.07 & $0.82^{\mathrm{b}}$ & 0.07 & $0.54^{\mathrm{c}}$ & 0.07 \\
\hline $22: 6 n-3$ & $3 \cdot 40^{\mathrm{a}}$ & 0.18 & $1.52^{\mathrm{b}}$ & $0 \cdot 18$ & $1.03^{b}$ & 0.18 \\
\hline Total $n$-3 PUFA & $10 \cdot 29^{a}$ & 0.29 & $10 \cdot 97^{\mathrm{a}}$ & 0.29 & $8.57^{\mathrm{b}}$ & 0.29 \\
\hline$n-3: n-6$ PUFA & $0.95^{\mathrm{a}}$ & 0.03 & $0.23^{\mathrm{C}}$ & 0.03 & $0.38^{b}$ & 0.03 \\
\hline
\end{tabular}

Ls, least square; $\mathrm{CP}$, crude protein; $\mathrm{CF}$, crude fat; $\mathrm{CHO}$, carbohydrates.

${ }_{a}, b, c$ Least square mean values within a row with unlike superscript letters were significantly different $(P<0.05)$ 
For further details on these and on the analytical methods of FA determination, see Rouvinen-Watt et $a l^{(3)}$ (Expt I) and $\operatorname{Dick}^{(7)}$ (Expt II). All procedures were carried out in accordance with the guidelines of the Canadian Council on Animal Care $^{(24)}$ and were approved by the Nova Scotia Agricultural College Animal Care and Use Committee (Expt I: ACUC file no. 2006-089; Expt II: ACUC file no. 2007-041).

\section{Molecular biology assays}

RNA extraction and purification. Total RNA content from the liver tissue was extracted using the RNeasy kit with QIAshredder homogenisers following the manufacturer's protocol (Qiagen). The purity of the isolated RNA was evaluated for potential protein, salt and ethanol contamination based on the ratio of absorbance readings at 260 and $280 \mathrm{~nm}$ $\left(A_{260} / A_{280}\right)$ and 260 and $230 \mathrm{~nm}\left(A_{260} / A_{230}\right)$ using the Nanodrop ND1000 spectrophotometer (Thermo Fisher Scientific). The quality was assessed by $0.7 \%$ agarose gel electrophoresis based on intact $28 \mathrm{~S}$ and $18 \mathrm{~S}$ ribosomal RNA bands. Following RNA isolation, first-strand complementary DNA was synthesised from $1 \mu \mathrm{g}$ of total RNA using MultiScribe ${ }^{\mathrm{TM}}$ RT primed with random primers, according to the manufacturer's protocol (High-Capacity complementary DNA Reverse Transcription Kit with RNAse Inhibitor; Applied Biosystems).

Gene sequencing. In order to obtain mink-specific sequences, forward and reverse primers were designed based on published canine, murine and human sequences using the GenBank and Primer3 databases (Whitehead Institute for Biomedical Research). The primers used for generating the mink sequences, the length of the resulting amplicons and the GenBank accession numbers are listed in Table 2. For hypoxanthine phosphoribosyltransferase 1 (HPRT1) primers, see also Pelletier et al. ${ }^{(25)}$. For PCR amplification, the reverse transcription product $(1 \mu \mathrm{l})$ was used as the template with $20 \mathrm{~mm}$-Tris-Cl (pH 8.4), $50 \mathrm{~mm}-\mathrm{KCl}, 1.5 \mathrm{~mm}-\mathrm{MgCl}_{2}, 0.2 \mathrm{~mm}$ each deoxyribonucleotide triphosphate, $0.24 \mu \mathrm{m}$ of each forward and reverse primer and $0 \cdot 8$ units of Taq Polymerase (Invitrogen), using the Dyad ${ }^{\circledR}$ Peltier Thermal Cycler (Bio-Rad). The PCR products were purified (Montage ${ }^{\mathrm{TM}}$ PCR Clean Up kit; Millipore) and sequenced at the Atlantic Research Centre for Agricultural Genomics at Nova Scotia Agricultural College using the Applied Biosystems 3130 DNA analyser (Life Technologies). Mink-specific gene sequences were generated for ACC-1, FAS and HPRT1. These nucleotide sequences, the inferred amino acid sequences and their GenBank accession numbers are reported in Table 3 .

Quantitative real-time PCR. For developing the quantitative real-time PCR (RT-qPCR) assays for the target gene mRNA, forward and reverse primers were designed based on the generated mink sequences presented in Table 3. Quantification of mRNA was done by RT-qPCR using the Lightcycler ${ }^{\circledR} 480$ II instrument (Roche) at the Atlantic Research Centre for Agricultural Genomics and reported according to the Bustin et al. ${ }^{(26)}$ MIQE guidelines. RT-qPCR assays were optimised for the quantification of mRNA encoding for the target proteins (i.e. genes of interest) using two reference genes, glyceraldehyde-3-phosphate dehydrogenase (GAPDH) and HPRT1, as normalising controls. Both have been recommended as stable reference genes for studies in the development of hepatic steatosis ${ }^{(27)}$. To quantify the mRNA of interest, copy RNAbased standards were prepared using the T7 promoter method $^{(28)}$. Each sample was run in triplicate with an acceptable $\mathrm{CV}<10 \%$. Table 4 displays the forward and reverse primers used for the qPCR assays for quantification of the mRNA levels of the target genes in mink liver tissue.

RT-qPCR conditions for a $10 \mu \mathrm{l}$ reaction were as follows: $1 \mu \mathrm{l}$ of a 1:10 dilution of sample complementary DNA, $1 \times$ GoTaq ${ }^{\circledR}$ Flexi buffer (Promega), $\mathrm{MgCl}_{2}, 0 \cdot 2 \mathrm{~mm}$ each deoxyribonucleotide triphosphate, specific forward and reverse primers (Table 4), fluorescent reporter dye and 0.8 units of GoTaq ${ }^{\circledR}$ HotStart Polymerase (Promega). GAPDH and HPRT1

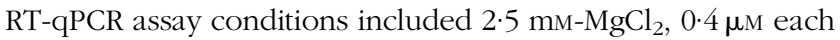
primer and $1 \times$ EvaGreen $^{\circledR}$ (Biotium). ACC- 1 and FAS RTqPCR assay conditions included 5 and $6 \mathrm{~mm}-\mathrm{MgCl}_{2}$, respectively, $0 \cdot 4 \mu \mathrm{M}$ each primer and $0 \cdot 25 \mathrm{X} \mathrm{SYBR}^{\circledR}$ Green I (Molecular Probes, Inc.). The assay was set up on Roche 384-well plates (catalogue no. 04729749001) using the Eppendorf epMotion 5075 (BioSystems Laboratory). For all RT-qPCR assays, the thermocycling conditions on the LightCycler ${ }^{\circledR} 480$ II included a hot-start pre-amplification of $2 \mathrm{~min}$ at $95^{\circ} \mathrm{C}$, PCR cycles consisting of denaturation at $95^{\circ} \mathrm{C}$ for $10 \mathrm{~s}$, annealing as specified below and extension at $72^{\circ} \mathrm{C}$ for $30 \mathrm{~s}$. This was followed by a preconditioning step of $95^{\circ} \mathrm{C}$ for $10 \mathrm{~s}, 65^{\circ} \mathrm{C}$ for $1 \mathrm{~min}, 70^{\circ} \mathrm{C}$ for $1 \mathrm{~s}$ and a melt cycle from 70 to $95^{\circ} \mathrm{C}$, with five acquisitions per $1^{\circ} \mathrm{C}$. The GAPDH real-time assay ran for forty PCR cycles, all other RT-qPCR assays for forty-five cycles. The annealing steps consisted of $61^{\circ} \mathrm{C}$ for $20 \mathrm{~s}$ (ACC-1), $65^{\circ} \mathrm{C}$ for $20 \mathrm{~s}$ (FAS), $61^{\circ} \mathrm{C}$ for $20 \mathrm{~s}$ (GAPDH) or $60^{\circ} \mathrm{C}$ for $30 \mathrm{~s}$ (HPRT1). The mRNA expression levels are reported as the ratio of the expression of genes of interest:reference genes. In Expt I, GAPDH was used as the reference, while in Expt II, HPRT1 was found to be non-responsive to treatments and was therefore the most suitable normalising control.

\section{Statistical analyses}

In Expt I, the experimental design used was $2 \times 6$ factorial with two sexes and six treatment groups. Data were analysed

Table 2. Forward and reverse primers used for PCR for generating mink-specific sequences for the target genes acetyl-CoA carboxylase-1 (ACC-1), fatty acid synthase (FAS) and hypoxanthine phosphoribosyltransferase 1 (HPRT1), length of the amplicon and the GenBank source

\begin{tabular}{lllcl}
\hline Target gene & Forward primer sequence $\left(5^{\prime}-3^{\prime}\right)$ & Reverse primer sequence $\left(5^{\prime}-3^{\prime}\right)$ & Amplicon (bp) & GenBank accession no./reference \\
\hline ACC-1 & ACATGAAGGCTGTGGTGATG & CTGTTTAGCGTGGGGATGTT & 652 & NM_198834 \\
& & & AY494006.1 \\
FAS & GAGGACGCCTTCCGATACAT & CAGAGGAGAAGGCCACAAAG & 557 & NM_017332 \\
HPRT1 & TGAACCAGGTTATGACCTAGATTATT & GGTCCTTTCACCAGCAAGCT & 466 & NM_001003357.1 \\
& TGACCAGGTTATGACCTAGATTTATT & GGCTTTGTATTTGCTTTTCCA & 616 & Pelletier et al. ${ }^{(25)}$ \\
\hline
\end{tabular}


Table 3. Mink-specific nucleotide sequences for acetyl-CoA carboxylase-1 (ACC-1), fatty acid synthase (FAS) and hypoxanthine phosphoribosyltransferase 1 (HPRT1) and the inferred amino acid sequences submitted to GenBank, National Center for Biotechnology Information

\section{Nucleotide sequence (bp)} ACC-1 (639)

FAS (516)

HPRT1 (521)

\section{Amino acid sequence} $A C C-1(212)$

FAS (171)

HPRT1 (173)
TGATGGATCTGCTGCGGCAGTATCTGCGAGTAGAGACCCAGTTCCAGAACGGTCACTATGACAAATGTGTGTTCGCCCTTCG AGAAGAGAACAAGAGTGACATGAACACAGTACTGAACTATATCTTCTCTCACGCCCAAGTCACCAAGAAGAATCTTCTGGTC ACAATGCTTATCGACCAGTTGTGCGGTCGGGACCCTACTCTCACCGATGAGCTGCTAAATATCCTTACAGAGCTCACTCAAC TCAGTAAGACCACCAACGCCAAAGTGGCACTTCGAGCACGCCAGGTTCTTATTGCCTCCCATTTGCCGTCATATGAGCTTCG CCATAACCAAGTAGAGTCCATCTTCCTTTCAGCAATTGACATGTACGGACATCAGTTTTGCATTGAGAACTTACAGAAACT CATCTTGTCTGAAACGTCTATTTTTGACGTCCTACCAAACTTCTTCTACCACAGCAACCAGGTAGTGAGGATGGCAGCTCT GGAGGTTTATGTTCGAAGGGCTTATATTGCCTATGAACTTAACAGTGTACAGCATCGCCAGCTTAAGGACAACACCTG TGTGGTGGAATTTCAGTTCATGCTGCCCACATCTCATCCAAACAGAGGGAACATCCCCACGCTAAACAGAA

GGCCCAGGGGAAGCACATCGGCAAAGTGGTGGTGCAGGTGCTCAAGGAGGAGCCAGAGGCAGGGCCACAGGTGCCCA GGCCCACGCTGATGACCGCGGTGTCCAAGACCTTCTGCCCAGCCCACAAGAGCTACATCATCACAGGCGGCCT

GGGCGGCTTCGGCCTGGAGCTGGCCCACTGGCTCGTGCTGCGCGGCGCCCAGAAGCTCGTGCTGACCTCTCGCTCCGGG ATCCGCACAGGCTACCAGGCCAAGCAAGTCCGCGAGTGGAGACGCCAGGGCGTGCAGGTCCTGGTGTCCACCAGCAAC GCCAGCTCGCTCGACGGGGCCCGGAACCTCATCGCGGAGGCCTCGCAGCTGGGGCCTGTGGGAGGCGTCTTCAACCTGG CCGTGGTCCTGAGAGACGCCGTGCTAGAGAATCAGACTCCTGAGTTCTTCCAGGACGTCAACAAGCCCAAGTACAGTGG CACCGTGAACTTGGACAGGGTGACCCGGGCGGCGTGCCCCGAGCTGGACTA

CTGTATACCTCATCATTACGCTGAGGATTTGGAAAAGGTGTTTATTCCTCATGGACTAATTATGGACAGGACCGAGCGGCTT

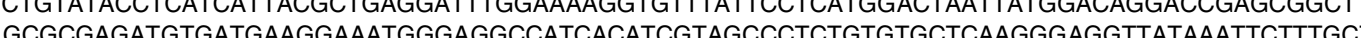
GCGCGATATG GACCTGCTGGATTATATCAAAGCACTGAACAGAAATAGTGATGGATCTATTCCCATGACTGTAGATTTCATCAGACTGAAGA GCTACTGTAATGACCAGTCAACAGGGGACATCAAAGTCATT GGTGGAGATGATCTCTCAACTT GACTGGAAAGAATGTCT GATTGTTGAGGATATAATTGACACTGGCAAAACAATGCAGACCTTGCTTTCCTTGGTCAAGGAACATAATCCAAAGATGGTC AAGGTCGCAAGCTTGCTGGTGAAGAGGACCTCTCGAAGTGTTGGCTATAAACCAGACTTTGTTGGATTTGAAATTCCCGAC AAGTTTGTTGTAGGATATGCCCTTGACTATA

MDLLRQYLRVETQFQNGHYDKCVFALREENKSDMNTVLNYIFSHAQVTKKNLLVTMLIDQLCGRDPTLTDELLNILTELTQLSKTTN AKVALRARQVLIASHLPSYELRHNQVESIFLSAIDMYGHQFCIENLQKLILSETSIFDVLPNFFYHSNQVVRMAALEVYVRRAYIA YELNSVQHRQLKDNTCVVEFQFMLPTSHPNRGNIPTLNR

AQGKHIGKVVVQVLKEEPEAGPQVPRPTLMTAVSKTFCPAHKSYIITGGLGGFGLELAHWLVLRGAQKLVLTSRSGIRTGYQAKQV REWRRQGVQVLVSTSNASSLDGARNLIAEASQLGPVGGVFNLAVVLRDAVLENQTPEFFQDVNKPKYSGTVNLDRVTRAACPELD CIPHHYAEDLEKVFIPHGLIMDRTERLARDVMKEMGGHHIVALCVLKGGYKFFADLLDYIKALNRNSDGSIPMTVDFIRLKSYCNDQS TGDIKVIGGDDLSTLTGKNVLIVEDIIDTGKTMQTLLSLVKEHNPKMVKVASLLVKRTSRSVGYKPDFVGFEIPDKFVVGYALDY
AY494006.2

FJ208799

AAR86714.2

$\mathrm{ACl} 42368$

AEO27861 
Table 4. Forward and reverse primers employed for the real-time quantitative PCR assays for quantifying mRNA levels of the target genes acetyl-CoA carboxylase-1 (ACC-1), fatty acid synthase (FAS), glyceraldehyde-3-phosphate dehydrogenase $(G A P D H)$ and hypoxanthine phosphoribosyltransferase 1 (HPRT1) in mink liver samples

\begin{tabular}{lllc}
\hline Target gene & Forward primer sequence $\left(5^{\prime}-3^{\prime}\right)$ & Reverse primer sequence $\left(5^{\prime}-3^{\prime}\right)$ & Amplicon (bp) \\
\hline ACC-1 & GCCCAAGTCACCAAGAAGAA & GCAAATGGGAGGCAATAAGA & 178 \\
FAS & ATCGGCAAAGTGGTGGTG & GCCGCCTGTGATGATGTAG & 132 \\
GAPDH & AATGCCTCCTGTACCACCAA & GGTCATGAGTCCCTCCACAA & 84 \\
HPRT1 & CTTTGCTGACCTGCTGGATT & CACCAATGACTTTGATGTCCC & 134 \\
\hline
\end{tabular}

using the General Linear Models procedure in SAS ${ }^{\circledR}$ version 9.2 (SAS Institute, Inc.) to examine the effects of sex and fasting regimens and their interaction on the measured variables. In Expt II, a split-split-plot factorial design was used, with fasting treatments as the whole plot, sex as the sub-plot and the sub-plot dietary treatments as the sub-sub-plots, with three replicates within each. Data were analysed using the Proc MIXED in SAS ${ }^{\circledR}$ version 9.2 to examine the effects of fasting, sex, dietary fat source and RDA on the response variables. A multiple means comparison test (PDiff) was used to identify where differences existed when these effects were found significant $(P<0 \cdot 05)$. Results are presented as least square means with their standard errors of the mean. To examine the relationships between the mRNA levels and other response variables, Pearson's correlation coefficients were calculated using SAS ${ }^{\circledR}$ version 9.2.

\section{Results}

In Expt I, significantly elevated levels of mRNA encoding for ACC-1 and FAS were observed in the liver of mink fasted for $5-7 d$, while upon re-feeding for $28 \mathrm{~d}$ after a $7 \mathrm{~d}$ food deprivation, the values returned to pre-fasting levels (effect of fasting: ACC-1, $P=0.006$; FAS, $P<0 \cdot 001$; Fig. 1(A) and $(\mathrm{B})$, respectively). Overall, the female mink expressed higher liver mRNA concentrations of ACC-1 and FAS than the males (effect of sex: ACC- $1, P=0.002$; FAS, $P=0.003$; Fig. 2(A) and (B), respectively). A strong linear relationship was observed between ACC-1 and FAS normalised to GAPDH as described by the following equation: FAS/ $\mathrm{GAPDH}=-0.007+10.915 \times(\mathrm{ACC}-1 / \mathrm{GAPDH}) ; \quad$ intercept $P=0 \cdot 001$, ACC $-1 /$ GAPDH $P<0 \cdot 001, R^{2} 0 \cdot 795$.

While ACC-1 and FAS correlated strongly with each other, they also correlated with the liver lipid content (Table 5). The liver fat content of mink in the $0,1,3,5,7 \mathrm{~d}$ and re-fed groups was on average 5.9 (SEM 1.5), 6.1 (SEM 1.5), 13.2 (SEM $1 \cdot 5$ ), $19 \cdot 0$ (SEM 1.5), $19 \cdot 7$ (SEM 1.4) and 5.3 (SEM 1.6) \%, respectively ${ }^{(3)}$. This corresponded with the following absolute amounts of total liver lipids: $0 \mathrm{~d}, 2.6$ (SEM 0.9) g; $1 \mathrm{~d}, 2.7$ (SEM 0.9) g; 3d, 6.2 (SEM 0.9) g; $5 \mathrm{~d}, 9.9$ (SEM 0.9) g; $7 \mathrm{~d}, 10 \cdot 2$ (sEM $0.9) \mathrm{g}$; re-fed, 2.6 (sem 1.0) g. The males had higher absolute amounts of total liver lipids (7.4 (SEM 0.5) g), as well as higher degrees of adiposity (34.8\% body fat) in comparison with the females (4.1 (sem 0.5$) \mathrm{g}, 31.3 \%)$.

In Expt II (Fig. 3), dietary fat source and feeding intensity had significant effects on ACC-1 mRNA (effect of diet $\times$ RDA interaction: $P=0 \cdot 040$ ). The highest expression was observed in the mink fed the rapeseed oil ( $n$-9) diet at $80 \%$ RDA and the lowest when the same diet was fed at $120 \%$ RDA.

For FAS, the highest gene expression was seen in the fasted mink fed at $80 \%$ RDA, while the lowest mRNA levels were detected in the non-fasted mink fed at $80 \%$ (fasting $\times$ RDA interaction: $P=0.006$; Fig. 4). Again, the two key enzymes of hepatic DNL were strongly correlated, and a significant correlation was observed between FAS and liver fat percentage (Table 5). Contrary to Expt I, ACC-1 did not correlate with liver fat percentage. A strong linear relationship was found
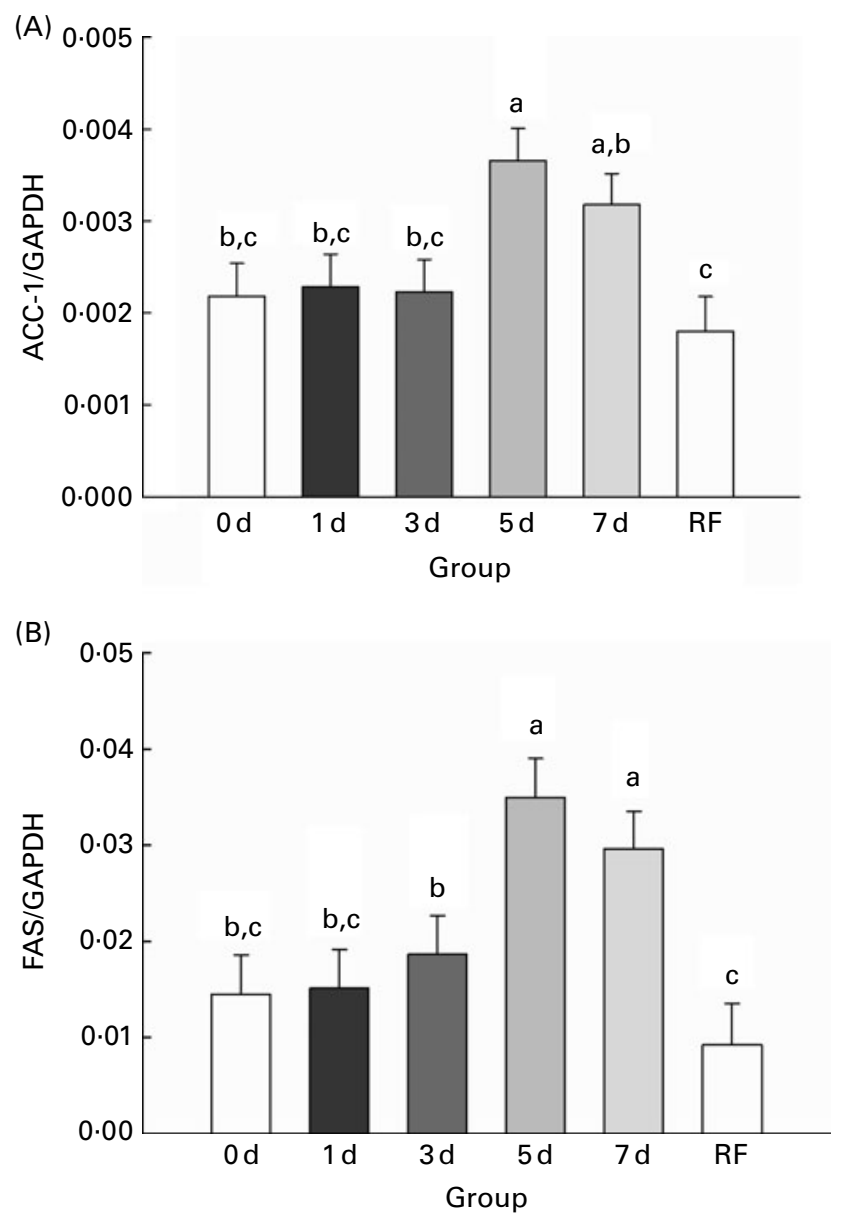

Fig. 1. Effect of fasting regimens of $0-7 d$ or re-feeding (RF) of $28 d$ after a $7 \mathrm{~d}$ fast on hepatic de novo lipogenesis in mink indicated by mRNA levels of (A) acetyl-CoA carboxylase-1 (ACC-1) and (B) fatty acid synthase (FAS) normalised to glyceraldehyde-3-phosphate dehydrogenase (GAPDH). Values are least square means of both sexes ( $n 60)$, with standard errors of the mean represented by vertical bars. ${ }^{a, b, c}$ Least square mean values with unlike letters were significantly different $(P<0.05)$. 

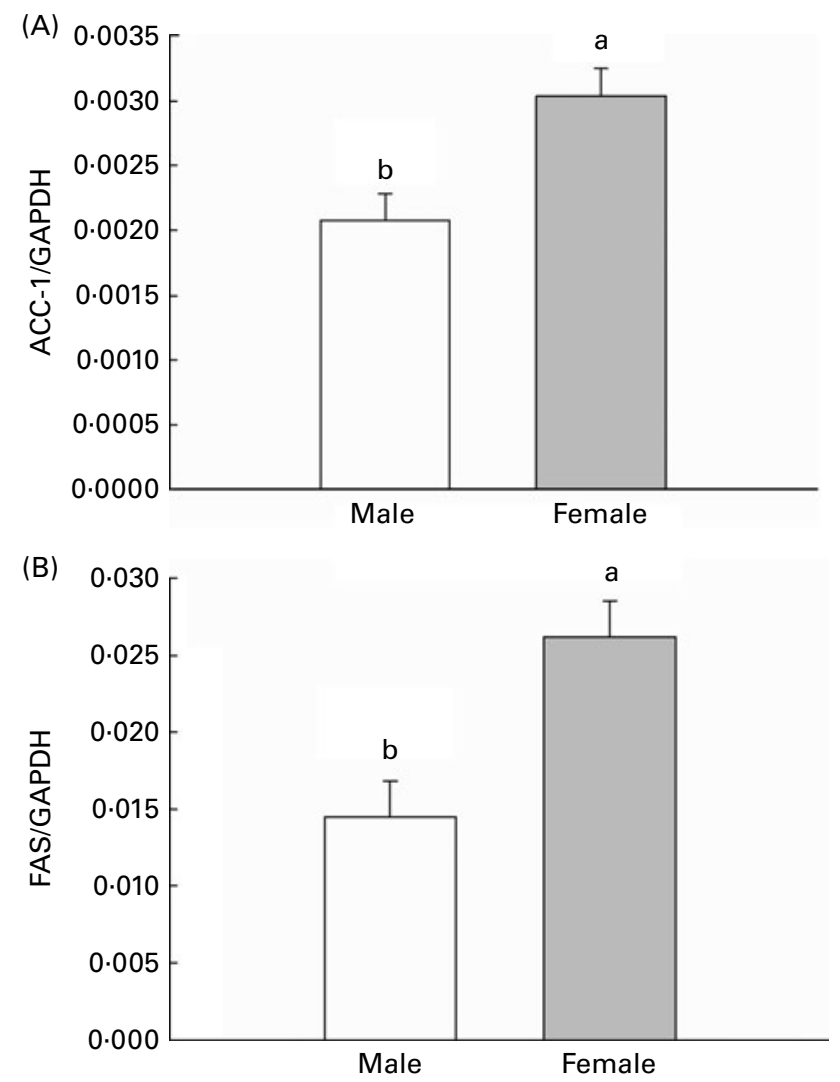

Fig. 2. Effect of sex on hepatic de novo lipogenesis in mink indicated by mRNA levels of (A) acetyl-CoA carboxylase-1 (ACC-1) and (B) fatty acid synthase (FAS) normalised to glyceraldehyde-3-phosphate dehydrogenase (GAPDH). Values are least square means of all experimental groups (fed and fasted; $n 60$ ), with standard errors of the mean represented by vertical bars. ${ }^{\mathrm{a}, \mathrm{b}}$ Least square mean values with unlike letters were significantly different $(P<0.05)$.

between ACC-1 and FAS normalised to HPRT1 as follows: FAS/HPRT1 $=-0 \cdot 114+15 \cdot 428 \times($ ACC-1/HPRT1 $) ; \quad$ intercept $P=0.015$, ACC-1/HPRT1 $P<0.001, R^{2} 0.604$.

In Expt $\mathrm{II}^{(7)}$, fasting resulted in significant increases in liver lipid content: $80 \% \mathrm{RDA}$, non-fasted $6.1 \% v$. fasted $16.1 \% ; 120 \%$ RDA, non-fasted $6.5 \% v$. fasted $21.7 \%$ (SEM $1 \cdot 1$; fasting $\times$ RDA interaction: $P=0 \cdot 015)$. Furthermore, a significant diet $\times$ RDA interaction was observed $(P=0.044)$. The liver lipid percentages of mink fed the rapeseed oil diet at both feeding intensities (80\% RDA: 12.5\%; 120\% RDA: $14.8 \%)$ and soyabean oil at $120 \%$ RDA (15.6\%) were higher than those in the mink fed soyabean oil at $80 \%$ RDA (9.0\%), while mink fed herring oil had intermediate levels of liver lipids (80\% RDA: $11.7 \%$; $120 \%$ RDA: $12 \cdot 0 \%$; SEM $1 \cdot 3 ; P<0 \cdot 05$ ).

For hepatic DNL FA (16:0, 18:0, 16:1n-7, 18:1n-9), a significant treatment effect was observed in Expt I. The mink fasted for 5-7d had higher relative amounts of C16 and C18 MUFA than the non-fasted mink, while the respective SFA were significantly reduced in response to food deprivation (Table 6). In Expt II, a fasting $\times$ diet $\times$ RDA interaction was present for all except 16:1n-7, where a significant fasting $\times$ RDA interaction was found. The C16 and C18 SFA were again lower in the fasted mink in all dietary treatment groups, whereas the respective MUFA were elevated (Table 7). For $16: 1 n-7$, the non-fasted $80 \%$ (2.78 (sEM $0.29) \mathrm{mol} \%)$ and $120 \%(3.19$ (SEM 0.31$) \mathrm{mol} \%)$ RDA groups did not differ from each other but differed from the fasted $80 \%$ RDA (5.60 (SEM 0.29) mol\%) and $120 \%$ RDA (8.79 (SEM $0 \cdot 29) \mathrm{mol} \%$ ). The latter two groups were also significantly different from each other. A trend was observed for the sex effect $(P=0.056)$; the female mink (5.49 (SEM 0.21) mol\%) had higher levels of $16: 1 n-7$ than the males (4.69) (sEM $0 \cdot 21) \mathrm{mol} \%$ ). In addition, the highest levels of $18: 1 n$-9 were found within the mink fed the rapeseed oil diet either at 80 or $120 \%$ RDA.

Hepatic C16 and C18 MUFA correlated significantly with the liver fat content in both experiments (Table 8). In Expt I, significant correlations were also found between MUFA and liver ACC-1 and FAS gene expression, whereas in Expt II, these relationships were less clear, with a significant correlation present only between FAS and the 18:1n-9 content.

\section{Discussion}

We have previously demonstrated that food deprivation for $3 \mathrm{~d}$ was adequate to induce hepatic lipidosis in mink with liver fat percentage increasing from about $6 \%$ in the non-fasted control group to above $13 \%$ in the fasted group ${ }^{(3)}$. Within two to four additional days of fasting, lipid accumulation increased further, reaching nearly $20 \%$ by the end of the $7 \mathrm{~d}$ fast. In the present study, significant increases were observed in the levels of mRNA encoding for ACC-1 and FAS at $5-7 \mathrm{~d}$ of fasting, suggesting that DNL further exacerbates liver fat accumulation. It is likely that the initial development of steatosis in the mink, the so-called 'first hit', takes place in response to rapid body fat mobilisation and subsequent increases in circulating NEFA concentrations by day 3 of food deprivation ${ }^{(2,29)}$. However, the present results show that this is followed by the activation of hepatic DNL. This strongly suggests that the development of fatty liver disease in the mink may be accompanied by the adipogenic transformation of hepatocytes, as seen in the human NAFLD, where the liver begins to express gene profiles characteristic of healthy adipose tissue ${ }^{(30,31)}$. Increased hepatic SREBP1-c:PPAR- $\alpha$ mRNA ratios have been found in patients with steatosis ${ }^{(20)}$, while recent

Table 5. Correlation of acetyl-CoA carboxylase-1 (ACC-1) and fatty acid synthase (FAS) normalised to glyceraldehyde-3-phosphate dehydrogenase (GAPDH; Expt I, $n$ 60) or hypoxanthine phosphoribosyltransferase 1 (HPRT1; Expt II, $n$ 72) with each other and with liver fat percentage, as indicators of hepatic de novo lipogenesis in mink

\begin{tabular}{lcr}
\hline Variables & $\begin{array}{c}\text { Correlation } \\
\text { coefficient, } r\end{array}$ & $P$ \\
\hline Expt I & & \\
ACC-1/GAPDH $v$. FAS/GAPDH & 0.891 & $<0.001$ \\
ACC-1/GAPDH v. liver fat percentage & 0.393 & 0.002 \\
FAS/GAPDH v. liver fat percentage & 0.527 & $<0.001$ \\
Expt II & & \\
ACC-1/HPRT1 v. FAS/HPRT1 & 0.777 & $<0.001$ \\
ACC-1/HPRT1 v. liver fat percentage & 0.038 & 0.749 \\
FAS/HPRT1 v. liver fat percentage & 0.330 & 0.005 \\
\hline
\end{tabular}




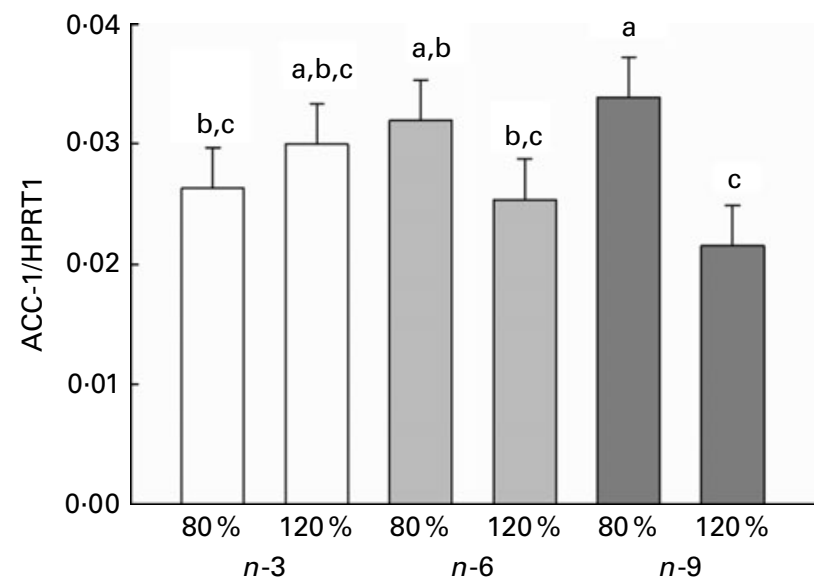

Fig. 3. Effect of dietary fatty acid source and feeding intensity (based on the RDA) on hepatic de novo lipogenesis in mink indicated by mRNA levels of acetyl-CoA carboxylase-1 (ACC-1) normalised to hypoxanthine phosphoribosyltransferase 1 (HPRT1). Values are least square means of both sexes from all experimental groups (fed and fasted; $n$ 72), with standard errors of the mean represented by vertical bars. Dietary fatty acid sources: $n-3$ (herring oil), $n-6$ (soyabean oil) or $n-9$ (rapeseed oil). ${ }^{a, b, c}$ Least square mean values with unlike letters were significantly different $(P<0.05)$.

research has also shown an up-regulation of PPAR- $\gamma^{(32)}$, reinforcing the role of SREBP-1c induction and DNL in the development of NAFLD. We propose that the up-regulation of hepatic DNL observed in the present study is an outcome of the initial development of steatosis and that $5-7 \mathrm{~d}$ is the critical time point for this to take place. The activation of the lipogenic pathways therefore contributes to the pathophysiology of fatty liver disease in mink during prolonged food deprivation, further advancing disease progression.

While the primary reason for the accumulation of TAG in the liver during the development of hepatic lipidosis in the mink is most probably the hydrolysis of storage TAG from adipose tissue causing increased influx of NEFA into the liver ${ }^{(29)}$, the present data suggest that liver DNL does play a role in further increasing the liver lipid load. Liver DNL results in the synthesis of C16 and C18 SFA, which can be further desaturated by stearoyl-CoA desaturase resulting in the formation of $\Delta$ 9-MUFA ${ }^{(33)}$. While the gene expression of stearoyl-CoA desaturase was not investigated in the present study, the fasted mink had higher hepatic C16 and C18 MUFA than the non-fasted mink. In Expt I, liver levels of these MUFA were highly correlated with the gene expression of the key enzymes for DNL. In addition, in Expt II, the highest levels of $18: 1 n-9$ and the highest liver TAG contents were found in the mink fed the rapeseed oil diet, either at 80 or $120 \%$ RDA; both variables correlating significantly with hepatic FAS expression. Further support to this lends the finding that in both experiments, liver total PUFA decreased in response to fasting ${ }^{(3,7)}$. PUFA of the $n-3$ and $n-6$ series are known to repress stearoyl-CoA desaturase gene expression and MUFA synthesis in the liver ${ }^{(34)}$.

It is well recognised that malonyl-CoA, an intermediate in the DNL pathway, is a potent inhibitor of carnitine-palmitoyl transferase $1^{(35)}$, which is responsible for a key step in FA oxidation, the transport of fatty acyl-CoA into the mitochondrion.
Thus, hepatic DNL suppresses fat oxidation. Further supporting this finding is that hepatic PPAR- $\alpha$, a key transcription factor controlling the expression of carnitine-palmitoyl transferase 1 , is down-regulated in obese patients with NAFLD $^{(20)}$. Hodson \& Frayn ${ }^{(36)}$ have recently postulated that the physiological significance of hepatic DNL may not be principally the quantitative contribution to FA supply, which is modest under most conditions, but may be its contribution to the regulation of fat oxidation via malonyl-CoA. It would be interesting to further examine whether FA oxidation is impaired in the mink with elevated hepatic DNL. If so, this may further compromise the liver's ability to deal with the excess lipid influx during rapid body fat mobilisation.

It is important to note that while liver is the primary site for DNL in humans and rodents, in strict carnivores such as the cat (Felis catus), adipose tissue serves this function, followed by liver, mammary glands and muscle ${ }^{(37)}$. Also, the precursors for DNL differ. While glucose is the precursor for DNL in humans, in cats, acetate supplies acetyl-CoA to ACC-1 for the conversion to malonyl-CoA, which provides two-carbon units to FAS for the synthesis of palmitate (16:0). The mink shares metabolic similarities with the hypercarnivorous domestic cat ${ }^{(38)}$. It is likely that DNL in the mink is also primarily located in adipose tissue, liver being a secondary site. It is also anticipated that the regulatory role of transcription factors, such as SREBP-1c, in the interface of carbohydrate and lipid metabolism differs between mink and non-carnivorous species $^{(37)}$. The substrate for hepatic DNL in the mink during fasting could be acetate resulting from incomplete FA oxidation (i.e. ketogenesis), which is typically enhanced in times of increased NEFA intake by the liver ${ }^{(39)}$.

The present results also show that genes encoding for the key enzymes of DNL were expressed at a higher level in the liver of the females in comparison with the males. The short-term food deprivation of mink results in the rapid

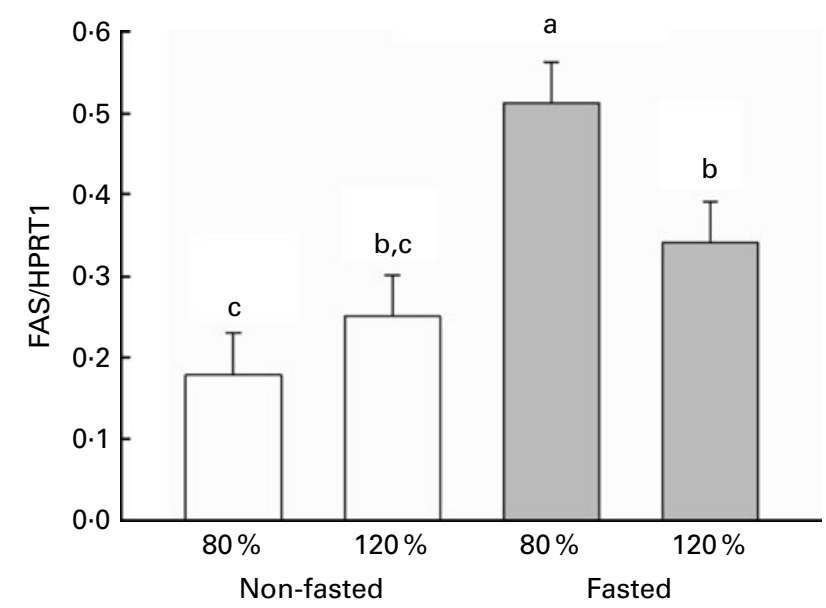

Fig. 4. Effect of fasting and feeding intensity (based on the RDA) on hepatic de novo lipogenesis in mink indicated by mRNA levels of fatty acid synthase (FAS) normalised to hypoxanthine phosphoribosyltransferase 1 (HPRT1). Values are least square means of both sexes from all dietary groups ( $n 72)$, with standard errors of the mean represented by vertical bars. ${ }^{\mathrm{a}, \mathrm{b}, \mathrm{c}}$ Least square mean values with unlike letters were significantly different $(P<0.05)$. 
Table 6. Effect of fasting on selected liver fatty acids in mink in Expt I

(Least square mean values with their standard errors)

\begin{tabular}{|c|c|c|c|c|c|c|c|c|c|c|c|c|}
\hline \multirow[b]{3}{*}{ Fatty acid (mol\%) } & \multicolumn{12}{|c|}{ Group } \\
\hline & \multicolumn{2}{|c|}{$0 d$} & \multicolumn{2}{|c|}{$1 d$} & \multicolumn{2}{|c|}{$3 d$} & \multicolumn{2}{|c|}{$5 d$} & \multicolumn{2}{|c|}{$7 d$} & \multicolumn{2}{|c|}{$\mathrm{RF}$} \\
\hline & Ls mean & SEM & Ls mean & SEM & Ls mean & SEM & Ls mean & SEM & Ls mean & SEM & Ls mean & SEM \\
\hline $16: 0$ & $26 \cdot 18^{a}$ & 0.38 & $25 \cdot 52^{\mathrm{a}}$ & 0.38 & $22 \cdot 50^{\mathrm{b}}$ & 0.38 & $21 \cdot 69^{\mathrm{b}, \mathrm{c}}$ & 0.38 & $20 \cdot 92^{c}$ & 0.36 & $26 \cdot 15^{a}$ & 0.40 \\
\hline $16: 1 n-7$ & $3.49^{d}$ & 0.39 & $4 \cdot 78^{c}$ & 0.39 & $7.48^{\mathrm{b}}$ & 0.39 & $8 \cdot 62^{a}$ & 0.39 & $9.07^{\mathrm{a}}$ & 0.37 & $3.63^{\mathrm{d}}$ & 0.41 \\
\hline $18: 0$ & $10 \cdot 02^{\mathrm{a}}$ & 0.37 & $7 \cdot 96^{\mathrm{b}}$ & 0.37 & $4.92^{\mathrm{C}}$ & 0.37 & $4.09^{c}$ & 0.37 & $3.95^{\mathrm{C}}$ & 0.36 & $8.94^{\mathrm{a}, \mathrm{b}}$ & 0.39 \\
\hline $18: 1 n-9$ & $21.98^{c}$ & 0.85 & $24 \cdot 14^{c}$ & 0.85 & $31 \cdot 11^{b}$ & 0.85 & $32 \cdot 93^{\mathrm{a}, \mathrm{b}}$ & 0.85 & $33.80^{\mathrm{a}}$ & 0.81 & $21.97^{c}$ & 0.91 \\
\hline
\end{tabular}

$R F$, re-fed; Ls, least square.

a,b,c,d Least square mean values within a row with unlike superscript letters were significantly different $(P<0.05)$.

mobilisation of body fat, most notably visceral, causing an elevated hepatosomatic index and increased liver TAG content $^{(3,5-7)}$. The increased absolute amounts of liver total phospholipids and phosphatidylcholine in these mink suggested endoplasmic reticulum stress ${ }^{(3)}$. During rapid BW loss, the hepatic lipid infiltration and the altered liver lipid profiles were associated with significantly reduced proportions of $n$ 3 PUFA in the liver, and the decrease was more evident in the females. It is noteworthy that the differences in the responses between sexes in hepatic ACC-1 and FAS expression became evident during $5-7 \mathrm{~d}$, while the females showed a faster decline in liver $n-3: n-6$ PUFA profiles already after $1 \mathrm{~d}$ of fasting ${ }^{(3)}$. This may explain the higher expression of mRNA encoding for ACC-1 and FAS in the female mink during food deprivation seen in the present study, as the depletion of $n-3$ LC-PUFA in relation to $n-6$ LC-PUFA has been shown to up-regulate lipogenesis ${ }^{(17)}$. It is possible that the elevated hepatic DNL gene expression in the female mink may be an adaptation to meet the augmented requirements of pregnancy and lactation.

The ACC-1 and FAS mRNA values were significantly correlated in both experiments and FAS also correlated with the liver lipid content, while ACC-1 showed correlation in Expt I only. The lipid synthesis pathways have been shown to be responsive to glucocorticoids and ghrelin, both directly ${ }^{(40,41)}$ and indirectly via activation of the endocannabinoid system $^{(18,22)}$. However, in response to fasting in Expt I, there was only a tendency towards lower glucocorticoid levels as shown by plasma cortisol concentrations, and no sex difference was observed ${ }^{(3)}$, while in Expt II, the cortisol levels were elevated in response to increased feeding intensity ${ }^{(7)}$. Furthermore, no consistent ghrelin response was present in Expt I. Similar to these findings, plasma ghrelin levels of the European polecat and the male American mink remained unaffected by food deprivation ${ }^{(42,43)}$, whereas in more leanbodied mustelids, plasma ghrelin concentrations increased in response to short-term food deprivation ${ }^{(44,45)}$. Elevated leptin concentrations, on the other hand, are linked to chronic inflammation and the development of insulin resistance, which in turn increases the transcription of SREBP-1c resulting in the up-regulation of DNL in the liver ${ }^{(46)}$. In Expt I, plasma leptin concentrations were lower in response to food deprivation and remained low thereafter ${ }^{(3)}$, while in Expt II, the highest leptin levels were observed in the non-fasted $120 \%$ RDA group and the lowest in the fasted mink (80 and $120 \%$ RDA), with the non-fasted $80 \%$ RDA mink being

Table 7. Effect of fasting, diet and feeding intensity on selected liver fatty acids in mink in Expt II

(Least square mean values with their standard errors)

\begin{tabular}{|c|c|c|c|c|c|c|c|c|c|c|c|c|}
\hline \multirow[b]{3}{*}{ Fatty acid (mol \%) } & \multicolumn{4}{|c|}{$n-3$ PUFA } & \multicolumn{4}{|c|}{$n-6$ PUFA } & \multicolumn{4}{|c|}{$n-9$ MUFA } \\
\hline & \multicolumn{2}{|c|}{$80 \%$} & \multicolumn{2}{|c|}{$120 \%$} & \multicolumn{2}{|c|}{$80 \%$} & \multicolumn{2}{|c|}{$120 \%$} & \multicolumn{2}{|c|}{$80 \%$} & \multicolumn{2}{|c|}{$120 \%$} \\
\hline & Ls mean & SEM & Ls mean & SEM & Ls mean & SEM & Ls mean & SEM & Ls mean & SEM & Ls mean & SEM \\
\hline \multicolumn{13}{|l|}{$16: 0$} \\
\hline Non-fasted & $26 \cdot 30^{\mathrm{a}}$ & 0.51 & $25 \cdot 00^{a}$ & 0.51 & $25 \cdot 61^{a}$ & 0.51 & $24 \cdot 86^{a}$ & 0.57 & $21.54^{b}$ & 0.51 & $20 \cdot 20^{\mathrm{b}}$ & 0.51 \\
\hline Fasted & $19 \cdot 51^{\mathrm{b}, \mathrm{c} *}$ & 0.51 & $21.04^{a *}$ & 0.51 & $20 \cdot 76^{a, b *}$ & 0.51 & $18 \cdot 63^{\mathrm{C} *}$ & 0.51 & $16 \cdot 18^{d_{*}}$ & 0.51 & $17 \cdot 81^{\mathrm{C*}}$ & 0.51 \\
\hline \multicolumn{13}{|l|}{$16: 1 n-7$} \\
\hline Non-fasted & 3.40 & 0.51 & 3.99 & 0.51 & $2 \cdot 48$ & 0.51 & $2 \cdot 48$ & 0.57 & 2.45 & 0.51 & 3.09 & 0.51 \\
\hline Fasted & $7 \cdot 21^{*}$ & 0.51 & $9 \cdot 36^{*}$ & 0.51 & $4 \cdot 19^{*}$ & 0.51 & $8.73^{*}$ & 0.51 & $5 \cdot 40^{*}$ & 0.51 & $8 \cdot 28^{*}$ & 0.51 \\
\hline \multicolumn{13}{|l|}{$18: 0$} \\
\hline Non-fasted & $9 \cdot 27^{a, b}$ & 0.51 & $9 \cdot 67^{\mathrm{a}, \mathrm{b}}$ & 0.51 & $10 \cdot 47^{a}$ & 0.51 & $10 \cdot 71^{a}$ & 0.57 & $9 \cdot 80^{a, b}$ & 0.51 & $8.41^{\mathrm{b}}$ & 0.51 \\
\hline Fasted & $4 \cdot 10^{\mathrm{b}, \mathrm{c} *}$ & 0.51 & $3.85^{\mathrm{b}, \mathrm{c} *}$ & 0.51 & $6 \cdot 67^{a *}$ & 0.51 & $3.53^{c *}$ & 0.51 & $4 \cdot 27^{\mathrm{b} *}$ & 0.51 & $3 \cdot 63^{\mathrm{c} *}$ & 0.51 \\
\hline \multicolumn{13}{|l|}{$18: 1 n-9$} \\
\hline Non-fasted & $15 \cdot 46^{\mathrm{c}}$ & 1.02 & $16 \cdot 38^{\mathrm{c}}$ & 1.02 & $14.54^{\mathrm{c}}$ & 1.02 & $13 \cdot 87^{c}$ & $1 \cdot 14$ & $26 \cdot 76^{\mathrm{b}}$ & 1.02 & $30 \cdot 16^{\mathrm{a}}$ & 1.02 \\
\hline Fasted & $27 \cdot 21^{\mathrm{b} *}$ & 1.02 & $26 \cdot 19^{\mathrm{b}, \mathrm{c} *}$ & 1.02 & $21 \cdot 80^{\mathrm{d} *}$ & 1.02 & $23 \cdot 89^{c, d_{*}}$ & 1.02 & $37 \cdot 73^{a *}$ & 1.02 & $35 \cdot 12^{a \star}$ & 1.02 \\
\hline
\end{tabular}

Ls, least square.

$\mathrm{a}, \mathrm{b}, \mathrm{c}, \mathrm{d}$ Least square mean values within a row with unlike superscript letters were significantly different $(P<0.05)$

* Least square mean values were significantly different between the non-fasted and fasted mink $(P<0.05)$. 
Table 8. Correlation of hepatic MUFA ( $\mathrm{mol} \%$ ) with liver fat percentage and with acetyl-CoA carboxylase-1 (ACC-1) and fatty acid synthase (FAS) normalised to glyceraldehyde-3-phosphate dehydrogenase (GAPDH; Expt I, $n$ 60) or hypoxanthine phosphoribosyltransferase 1 (HPRT1; Expt II, $n$ 72) in mink

\begin{tabular}{lcr}
\hline Variables & Correlation coefficient, $r$ & $P$ \\
\hline Expt I & & \\
$16: 1 n-7$ v. liver fat percentage & 0.869 & $<0.001$ \\
$18: 1 n-9$ v. liver fat percentage & 0.797 & $<0.001$ \\
ACC-1/GAPDH $v .16: 1 n-7$ & 0.343 & 0.007 \\
ACC-1/GAPDH $v .18: 1 n-9$ & 0.424 & $<0.001$ \\
FAS/GAPDH $v .16: 1 n-7$ & 0.433 & $<0.001$ \\
FAS/GAPDH $v .18: 1 n-9$ & 0.529 & $<0.001$ \\
Expt II & & \\
$16: 1 n-7$ v. liver fat percentage & 0.809 & $<0.001$ \\
18: $1 n-9$ v. liver fat percentage & 0.586 & $<0.001$ \\
ACC-1/HPRT1 v. $16: 1 n-7$ & -0.094 & 0.436 \\
ACC-1/HPRT1 v. $18: 1 n-9$ & 0.031 & 0.799 \\
FAS/HPRT1 v. $16: 1 n-7$ & 0.179 & 0.134 \\
FAS/HPRT1 v. $18: 1 n-9$ & 0.275 & 0.020 \\
\hline
\end{tabular}

intermediate $^{(7)}$. These endocrine regulators thus seem to be of little importance in controlling hepatic DNL in the mink during the development of fatty liver disease.

In Expt II, when fed different dietary fat sources at two dietary allowance levels, fasting and the lower feeding intensity resulted, as expected, in lower BW in the mink ${ }^{(7)}$. Increased liver fat content was observed in the fasted mink, and it was the most severe in the fasted $120 \%$ RDA groups. In the present study, increased DNL, as indicated by the elevated ACC-1 mRNA values, was observed in the liver of the mink when provided diets with rapeseed oil ( $n-9$ FA) and fed restrictively, while hepatic DNL was suppressed when the mink were fed the same diet $20 \%$ above the RDA. Furthermore, fasting of the mink following restrictive feeding resulted in the up-regulation of hepatic FAS, while in the non-fasted restrictively fed mink, low expression levels of FAS were observed. It has recently been shown in rats (Rattus norvegicus) that significant differences exist between different adipose tissue depots in the expression of lipogenic genes in response to dietary $n-3$ and $n-6$ PUFA $^{(47)}$, while the present data suggest that hepatic DNL may differ between the levels of feeding intensity depending on the dietary fat source and, when feed allowance is reduced, between the fasted and non-fasted states. It is likely that the up-regulation of DNL observed in the present study in the $80 \%$ RDA rapeseed oil diet group may have significantly contributed to the increased liver lipid percentage in this group by both increasing FA synthesis and reducing oxidation $^{(36)}$, while in the $120 \%$ RDA rapeseed oil group, the lipids may have been mostly derived from hydrolysed adipose tissue depots. To confirm these findings, further research into the effects of dietary FA supply and feeding intensity on lipogenic pathways in the liver and adipose tissue is warranted. Also, while the tissues in the present study were harvested following fasting, either overnight or longer, it would be useful to examine individuals in the postprandial state, as this may also have an impact on DNL gene expression.

Based on the results of the present study, DNL is upregulated in response to $5-7 \mathrm{~d}$ food deprivation and therefore plays a role in liver lipid accumulation during the development of hepatic steatosis in the mink, especially in the females. In human NAFLD, increased hepatic DNL has been reported, although serum NEFA are clearly the dominant contributors to liver TAG pools ${ }^{(48)}$. Donnelly et al. ${ }^{(48)}$ also argue that one of the underlying causes of fat accumulation in NAFLD is the inability of the liver to regulate changes in DNL during the transition from the fasted to the fed state. In the present study, however, liver DNL was shown to return to pre-fasting levels after normal feeding was resumed for $28 \mathrm{~d}$. It is most likely that the primary cause for the development of hepatic lipidosis in the mink in response to short-term food deprivation is the rapid hydrolysis of (visceral) adipose tissue depots ${ }^{(3)}$. NEFA released into the hepatic portal circulation overwhelm the liver's ability to secrete the accumulated TAG as VLDL or alternatively oxidise the NEFA for energy purposes ${ }^{(2,29,49)}$. In addition, the fasted mink catabolise body proteins to maintain blood glucose levels and have been shown to have lower plasma arginine levels ${ }^{(50)}$. Arginine is required for the functioning of the urea cycle and its deficiency results in the accumulation of orotic $\operatorname{acid}^{(51)}$, a hepatotoxic metabolite which interferes with VLDL assembly and secretion ${ }^{(52)}$. In the present study, plasma TAG were increased in response to food deprivation in both experiments ${ }^{(3,7)}$. It is noteworthy that in Expt I, plasma TAG reached their peak on days 3-5 of fasting and returned to pre-fasting levels upon re-feeding ${ }^{(3)}$. The lower circulating TAG observed on day 7 could indicate reduced hepatic TAG secretion in $\mathrm{VLDL}^{(33)}$. The rapidity of the development of hepatic lipidosis in the mink is probably an outcome of the complex biochemical interactions that exist among the different physiological systems during food deprivation. These exert pathophysiological linkages between liver lipid metabolism, gluconeogenetic pathways and the urea cycle function ${ }^{(3)}$. The results of the present study provide first evidence that hepatic DNL is involved in the development of fatty liver disease in the American mink.

\section{Conclusions}

The present data show that (1) fasting for 5-7d significantly increased the expression of mRNA encoding for ACC-1 and FAS, key enzymes of hepatic DNL, as well as the proportions of C16 and 18 MUFA in the liver of the mink, (2) the female mink had higher hepatic DNL than the males, (3) ACC-1 and FAS mRNA returned to pre-fasting levels in response to $28 \mathrm{~d}$ re-feeding, (4) ACC-1 and FAS correlated strongly with each other and moderately with the liver lipid content, (5) feeding at $80 \%$ RDA with rapeseed oil as the dietary fat source resulted in the highest ACC-1 expression, while the same diet fed at $120 \%$ suppressed ACC-1 mRNA levels and (6) the highest gene expression for FAS was seen in the fasted mink fed at $80 \%$ RDA, while the lowest FAS mRNA levels were detected in the non-fasted mink fed at $80 \%$. It is evident that shortterm food deprivation induces hepatic lipidosis in the mink and that during this process, hepatic DNL further exacerbates liver fat accumulation. 


\section{Acknowledgements}

We thank the staff of the Canadian Centre for Fur Animal Research for their skilful technical assistance during the animal experiments. This study was supported by the Nova Scotia Department of Agriculture Technology Development Program (DEV26-001, DEV27-016), the Natural Sciences and Engineering Research Council of Canada (Discovery Grant to K. R.-W.), the Agriculture and Agri-Food Canada, the Canada Mink Breeders' Association and the Chinese Ministry of Education (travel stipend to S. L.). K. R.-W., A.-M. M. and P. N. jointly planned this research, while K. R.-W. oversaw all the experimental procedures. M. D. and S. L. participated in Expt II, and L. H., C. P. and S. L. carried out the laboratory analyses. Data analysis and manuscript writing were led by K. R.-W., with contributions from all co-authors. The authors declare that they have no conflict of interest.

\section{References}

1. Rouvinen-Watt K (2003) Nursing sickness in the mink - a metabolic mystery or a familiar foe? Can J Vet Res $\mathbf{6 7}$, $161-168$.

2. Adams LA, Angulo P \& Lindor KD (2005) Nonalcoholic fatty liver disease. Can Med Ass J 172, 899-905.

3. Rouvinen-Watt K, Mustonen A-M, Conway R, et al. (2010) Rapid development of fasting-induced hepatic lipidosis in the American mink (Neovison vison): effects of food deprivation and re-alimentation on body fat depots, tissue fatty acid profiles, hematology and endocrinology. Lipids $\mathbf{4 5}$, 111-128.

4. Damgaard BM, Clausen TN \& Henriksen P (1994) Effect of protein and fat content in feed on plasma alanine-aminotransferase and hepatic fatty infiltration in mink. $J$ Vet Med A 41, 620-629.

5. Bjornvad CR, Elnif J \& Sangild PT (2004) Short-term fasting induces intra-hepatic lipid accumulation and decreases intestinal mass without reduced brush-border enzyme activity in mink (Mustela vison) small intestine. J Comp Physiol B 174, 625-632.

6. Mustonen A-M, Pyykönen T, Paakkonen T, et al. (2005) Adaptations to fasting in the American mink (Mustela vison): carbohydrate and lipid metabolism. Comp Biochem Physiol A 140, 195-202.

7. Dick MF (2010) Fatty liver syndrome in mink - causes and metabolic consequences. M.Sc. thesis. Dalhousie University and Nova Scotia Agricultural College.

8. Nieminen P, Käkelä R, Pyykönen T, et al. (2006) Selective fatty acid mobilization in the American mink (Mustela vison) during food deprivation. Comp Biochem Physiol B 145, 81-93.

9. Nieminen P, Mustonen A-M, Kärjä V, et al. (2009) Fatty acid composition and development of hepatic lipidosis during food deprivation - mustelids as a potential animal model for liver steatosis. Exp Biol Med 234, 278-286.

10. Rouvinen K \& Kiiskinen T (1989) Influence of dietary fat source on the body fat composition of mink (Mustela vison) and blue fox (Alopex lagopus). Acta Agric Scand 39, 279-288.

11. Käkelä R, Pölönen I, Miettinen M, et al. (2001) Effects of different fat supplements on growth and hepatic lipids and fatty acids in male mink. Acta Agric Scand A 51, 217-223.

12. Videla LA, Rodrigo R, Araya J, et al. (2004) Oxidative stress and depletion of hepatic long-chain polyunsaturated fatty acids may contribute to nonalcoholic fatty liver disease. Free Radic Biol Med 37, 1499-1507.

13. Iritani N \& Fujikawa S (1982) Competitive incorporation of dietary $\omega-3$ and $\omega-6$ polyunsaturated fatty acids into the tissue phospholipids in rats.J Nutr Sci Vitaminol 28, 621-629.

14. El-Badry AM, Graf R \& Clavien PA (2007) Omega 3 - Omega 6: what is right for the liver? J Hepatol 47, 718-725.

15. Osborne TF (2000) Sterol regulatory element-binding proteins (SREBPs): key regulators of nutritional homeostasis and insulin action. J Biol Chem 275, 32379-32382.

16. Clarke SD, Thuillier P, Baillie RA, et al. (1999) Peroxisome proliferator-activated receptors: a family of lipid-activated transcription factors. Am J Clin Nutr 70, 566-571.

17. Clarke SD (2001) Polyunsaturated fatty acid regulation of gene transcription: a molecular mechanism to improve the metabolic syndrome. J Nutr 131, 1129-1132.

18. Engeli S, Böhnke J, Feldpausch M, et al. (2005) Activation of the peripheral endocannabinoid system in human obesity. Diabetes 54, 2838-2843.

19. Osei-Hyiaman D, DePetrillo M, Pacher P, et al. (2005) Endocannabinoid activation at hepatic $\mathrm{CB}_{1}$ receptors stimulates fatty acid synthesis and contributes to diet-induced obesity. J Clin Invest 115, 1298-1305.

20. Pettinelli P, del Pozo T, Araya J, et al. (2009) Enhancement in liver SREBP-1C/PPAR- $\alpha$ ratio and steatosis in obese patients: correlations with insulin resistance and $n-3$ long-chain polyunsaturated fatty acid depletion. Biochim Biophys Acta 1792, 1080-1086.

21. Berger A, Crozier G, Bisogno T, et al. (2001) Anandamide and diet: inclusion of dietary arachidonate and docosahexaenoate leads to increased brain levels of the corresponding $\mathrm{N}$-acetylethanolamines in piglets. Proc Natl Acad Sci US A 98, 6402-6406.

22. Di S, Malcher-Lopez R, Marcheselli VL, et al. (2005) Rapid glucocorticoid-mediated endocannabinoid release and opposing regulation of glutamate and $\gamma$-aminobutyric acid inputs to hypothalamic magnocellular neurons. Endocrinology 145, 4292-4301.

23. Rouvinen-Watt K, White MB \& Campbell R (2005) Mink Feeds and Feeding. Ontario Ministry of Agriculture and Food, through the Agricultural Research Institute of Ontario, and the Nova Scotia Agricultural College.

24. Canadian Council on Animal Care (CCAC) (1993) Guide to the Care and Use of Experimental Animals, vol. 1 [ED Olfert, BM Cross and AA McWilliam, editors] Ottawa: CCAC.

25. Pelletier R-M, Akpovi CD, Chen L, et al. (2011) CX43 expression, phosphorylation, and distribution in the normal and autoimmune orchitic testis with a look at gap junctions joining germ cell to germ cell. Am J Physiol Regul Integr Comp Physiol 300, R121-R139.

26. Bustin SA, Benes V, Garson JA, et al. (2009) The MIQE guidelines: minimum information for publication of quantitative real-time PCR experiments. Clin Chem 55, 611-622.

27. Xu L, Ma X, Cui B, et al. (2011) Selection of reference genes for qRT-PCR in high fat diet-induced hepatic steatosis mice model. Mol Biotechnol 48, 255-262.

28. Fronhoffs S, Totzke G, Stier S, et al. (2002) A method for the rapid construction of cRNA standard curves in quantitative real-time reverse transcription polymerase chain reaction. Mol Cell Probes 16, 99-110.

29. Dowman JK, Tomlinson JW \& Newsome PN (2010) Pathogenesis of non-alcoholic fatty liver disease. Q J Med 103, 71-83.

30. Westerbacka J, Kolak M, Kiviluoto T, et al. (2007) Genes involved in fatty acid partitioning and binding, lipolysis, monocyte/macrophage recruitment, and inflammation are 
overexpressed in the human fatty liver of insulin-resistant subjects. Diabetes 56, 2759-2765.

31. Pardina E, Baena-Fustegueras JA, Llamas R, et al. (2009) Lipoprotein lipase expression in livers of morbidly obese patients could be responsible for liver steatosis. Obes Surg 19, 608-616.

32. Pettinelli P \& Videla LA (2011) Up-regulation of PPAR- $\gamma$ mRNA expression in the liver of obese patients: an additional reinforcing lipogenic mechanism to SREBP-1c induction. $J$ Clin Endocrinol Metab 96, 1424-1430.

33. Nagle CA, Klett EL \& Coleman RA (2009) Hepatic triacylglycerol accumulation and insulin resistance. J Lipid Res 50, S74-S79.

34. Ntambi JM (1999) Regulation of stearoyl-CoA desaturase by polyunsaturated fatty acids and cholesterol. J Lipid Res 40, 1549-1558.

35. Saggerson D (2008) Malonyl-CoA, a key signaling molecule in mammalian cells. Annu Rev Nutr 28, 253-272.

36. Hodson L \& Frayn K (2011) Hepatic fatty acid partitioning. Curr Opin Lipidol 22, 216-224.

37. Bergen WG \& Mersmann HJ (2005) Comparative aspects of lipid metabolism: impact on contemporary research and use of animal models. J Nutr 135, 2499-2502.

38. Eisert R (2011) Hypercarnivory and the brain: protein requirements of cats reconsidered. J Comp Physiol B 181, 1-17.

39. Nguyen P, Leray V, Diez M, et al. (2008) Liver lipid metabolism. J Anim Physiol Anim Nutr 92, 272-283.

40. Bernadier CD (1989) Role of glucocorticoids in the regulation of lipogenesis. FASEB J 3, 2179-2183.

41. Perez-Tilve D, Heppner K, Kirchner H, et al. (2011) Ghrelininduced adiposity is independent of orexigenic effects. FASEB J 25, 2814-2822.

42. Mustonen A-M, Saarela S, Pyykönen T, et al. (2005) Endocrinologic adaptations to wintertime fasting in the male American mink (Mustela vison). Exp Biol Med 230, 612-620.
43. Mustonen A-M, Puukka M, Rouvinen-Watt K, et al. (2009) Response to fasting in an unnaturally obese carnivore, the captive European polecat Mustela putorius. Exp Biol Med 234, 1287-1295.

44. Mustonen A-M, Puukka M, Saarela S, et al. (2006) Adaptations to fasting in a terrestrial mustelid, the sable (Martes zibellina). Comp Biochem Physiol A 144, 444-450.

45. Nieminen P, Rouvinen-Watt K, Saarela S, et al. (2007) Fasting in the American marten (Martes americana): a physiological model of the adaptations of a lean-bodied animal. $J$ Comp Physiol B 177, 787-795.

46. Meshkani R \& Adeli K (2009) Hepatic insulin resistance, metabolic syndrome and cardiovascular disease. Clin Biochem 42, 1331-1346.

47. Muhlhausler BS, Cook-Johnson R, James M, et al. (2010) Opposing effects of omega- 3 and omega-6 long chain polyunsaturated fatty acids on the expression of lipogenic genes in omental and retroperitoneal adipose depots in the rat. $J$ Nutr Metab (epublication ahead of print version 5 August 2010).

48. Donnelly KL, Smith CI, Schwarzenberg SJ, et al. (2005) Sources of fatty acids stored in liver and secreted via lipoproteins in patients with nonalcoholic fatty liver disease. J Clin Invest 115, 1343-1351.

49. Bergman RN (2000) Non-esterified fatty acids and the liver: why is insulin secreted into the portal vein? Diabetologia 103, 946-952.

50. Mustonen A-M, Puukka M, Pyykönen T, et al. (2005) Adaptations to fasting in the American mink (Mustela vison): nitrogen metabolism. J Comp Physiol B 175, 357-363.

51. Damgaard BM (1998) Effects of dietary supply of arginine on urinary orotic acid excretion, growth performance and blood parameters in growing mink (Mustela vison) kits fed lowprotein diets. Acta Agric Scand A 48, 113-121.

52. Cornelius LM \& Jacobs G (1989) Feline hepatic lipidosis. In Current Veterinary Therapy X: Small Animal Practice, pp. 869-873 [RW Kirk, editor]. Philadelphia: WB Saunders. 